\title{
Structure and mechanical properties of A356-C alloys
}

\author{
Marina Khmeleva $^{1, *}$, Anton Khrustalev ${ }^{1}$ and Alexander Vorozhtsov $^{1}$ \\ ${ }^{1}$ National Research Tomsk State University, Russia, Tomsk, 36 Lenin Ave., 634050
}

\begin{abstract}
The paper deals with influence of mechanical mixing and vibration treatment on the structure and mechanical characteristics of the aluminum alloy containing $\leq 1$ wt. $\%$ of nanodiamonds (A356-C). The alloy was obtained from industrial A356 Al-Si casting alloy by means of an integrated effect of mechanical mixing and vibration. It has been shown that the introduction of nanodiamond particles contributes to improving the alloy structure and increasing its mechanical tensile properties. The structure of the A356 aluminum alloy has been refined with introduction of $0.2 \mathrm{wt} \%$ nanodiamonds and application of vibration melt treatment. The introduction of nanodiamonds into the melt and the vibration melt treatment enable one to increase the yield strength and tensile strength of the A356 aluminum alloy without any change in ductility.
\end{abstract}

\section{Introduction}

Metal casting is one of the most important industrial processes offering a variety of advantages, such as the possibility to inject into a mold, the efficient use of metals, and high performance with minimal labour intensity, etc. [1]. In recent years, materials industry has caused increasing interest in aluminum alloys production. Meanwhile, Al-based and Al-Si alloys characterized by good mechanical and metallurgical properties have attracted the attention among cast alloys [2]. However, further improvement of mechanical properties for aluminum alloys is a major challenge for metallurgy.

It is known that the formation of fine-grained texture for Al-alloys is a most important condition for obtaining high-quality alloys. Many researchers and metal scientists have developed various methods to control the alloy structure and helped to implement these methods in manufacturing, thereby allowing one to influence a number of their properties [3-8]. The application of hardening non-metallic particles is an urgent issue for improving the cast alloy structure due to the grinding of structural components ( $\alpha-\mathrm{Al}$ solid solution, $\alpha-\mathrm{Al}+\mathrm{Si}$ eutectic phases). At present, there are quite a number of experimental data on the use of metal oxides $\left(\mathrm{Al}_{2} \mathrm{O}_{3}\right.$, $\mathrm{TiO}_{2}$ ), carbides and borides for modification of the Al-Si alloy grain structure [9-13]. Carbon nanomaterials (carbon nanotubes, fullerene and shungite carbon) are also widely used for the grain structure refinement and the improvement of mechanical properties for aluminum alloys [14-15]. The injection of diamond nanoparticles (DNPs) obtained by the detonation of high explosives into aluminum matrix is of particular importance [16]. DNPs are an example of nanomaterials which production was fully deployed and commercialized [17]. The interest in nanodiamonds is caused by combining their unique properties: high hardness and inertness of diamond nanoparticles with a high chemical activity of porous amorphous shells on their cores, their resistance to attack by corrosive media, etc. [18]. High dispersion of detonation nanodiamonds can significantly change properties of composite materials when introduced in a relatively small volume fraction [19].

Thus, it was shown that nanodiamond particles allow effectively managing aluminum alloy properties. Meanwhile, there is a fact about a possible non-uniform distribution of introduced refractory particles within the ingot structure. To address this concern, various kinds of external influences on liquid metals are used. There are a large number of studies to examine ultrasound $[20,21]$ and electromagnetic [22] effects on aluminum liquid metals. The vibration treatment is a method of external physical impact on liquid metals that is applied to improve their microstructure and, therefore, mechanical properties during crystallization. The vibration treatment (VT) is a cost-reserved and simple method to control the crystallization process with high performance. It also does not require high energy consumption.

A number of studies have been conducted to explore the vibration effect on alloy properties [23, 24]. It was concluded that the oscillation superposition causes the cavitation which destroys growing crystals. It was experimentally shown that the decrease in grain size provoked growth of the vibration frequency up to a certain value [25-27]. Many papers were also devoted to examining the influence of low-frequency vibrations on crystallization processes and the formation of finegrained texture. However, issues related to the effects of vibration and modifying particles on the structure change and the improvement of mechanical properties for aluminum alloys remain unclear and require further study and discussion. It is important to investigate the integrated effect of modification and vibration on the

*Corresponding author: khmelmg@gmail.com 
crystallization and mechanical properties of Al-Si alloys. At the same time, the wettability of nanoparticles will be the main factor influencing their introduction and distribution during the vibration treatment.

The aim of this research was to determine the effect of DNPs and the vibration treatment on the structure and mechanical properties of the A356 aluminum alloy.

\section{Materials and methods}

The A356 aluminum alloy (Al-Si system, GOST RF 1583-93 Russia) based on the Al-Si system was used as a matrix alloy. The DNP (Fig.1) obtained by detonation synthesis was used for alloy hardening [28, 29]. To improve the wettability of DNPs, they were premixed with micro-sized aluminum powder and the resulting mixture was wrapped with aluminum foil.

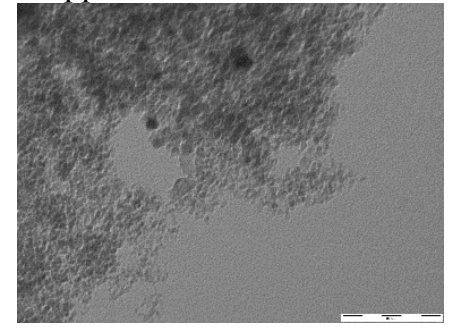

Fig. 1. SEM image of nanodiamond powder ("FSPC “Altai”, Russia).

The A356 alloy was placed in a crucible located in an enclosed-type furnace at $800{ }^{\circ} \mathrm{C}$. Then, using a gripper we removed the crucible from the furnace and poured the liquid metal at $700{ }^{\circ} \mathrm{C}$ in a preheated chill mold with a cylindrical cavity (diameter of $30 \mathrm{~mm}$ and a height of $110 \mathrm{~mm}$ ) which was located on a vibrating table. The vibration frequency was $60 \mathrm{~Hz}$, the amplitude was 0.53 $\mathrm{mm}$ (a schematic representation of the process is shown in Fig. 2).
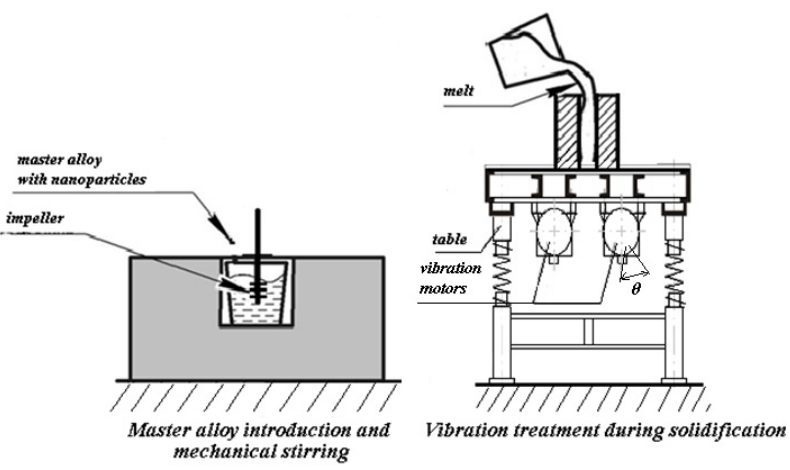

Fig. 2. Schematic representation of the vibration effect on the melt.

Another experiment was carried out to evaluate the integrated effect of nanoparticle modification and vibration. A rod-shaped container with DNPs was heated in the furnace at $200{ }^{\circ} \mathrm{C}$. The special mixing device (the device consisted of several perforated disks with openings and pins made of commercially pure titanium; the rotational speed was $1500 \mathrm{rpm}$ ) was used to provide a uniform distribution of DNPs within the melt volume. The mixing device was completely immersed in the molten metal. Then a container with DNPs was fed into the mixing zone for $30 \mathrm{sec}$ mixing with the subsequent casting at $250{ }^{\circ} \mathrm{C}$ into the steel chill mold located on the vibrating table (Fig.2. The content of DNPs in the alloy was 0.2 and $1 \mathrm{wt} \%$.

The structure of obtained materials was studied by an optic microscope Olympus GX71 (Olympus, Japan). The microstructure was achieved by mechanical polishing and electrochemical oxidation with 5\% fluoroboric acid at the voltage of $20 \mathrm{~V}$ and current of $1 \mathrm{~A}$. An universal testing machine Instron 3369 (Instron, USA) was used for mechanical tensile testing of the alloys. The density of the alloy samples was determined by a hydrostatic weighing method using the following formula:

$$
\rho=\frac{m}{V}
$$

where $\mathrm{m}$ was the sample mass, $\mathrm{V}$ - the sample volume, calculated as the difference between its mass in air and in water.

The tensile test samples were in a shape of flat blades with a useful cross section of $1 \times 6 \mathrm{~mm}$ and a length of 35 $\mathrm{mm}$. The strain rate was $0.001 \mathrm{~s}^{-1}$, while the test temperature was $23{ }^{\circ} \mathrm{C}$. Three samples were tested for each alloy.

\section{Results and discussion}

Fig. 3 shows optical images of the initial A356 alloy surface and that of A356 alloys with DNPs (0.2 wt $\%$ and $1 \mathrm{wt} \%$ ) in two modes: before and after the vibration effect.

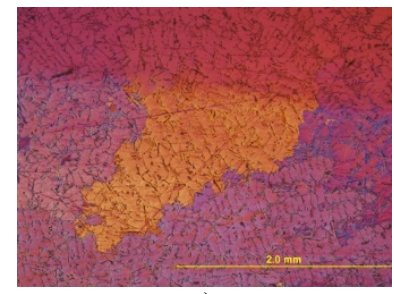

a)

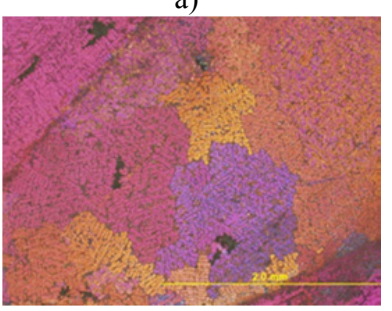

c)

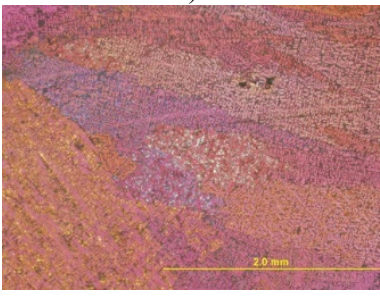

e)

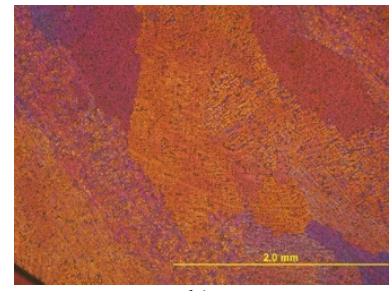

b)

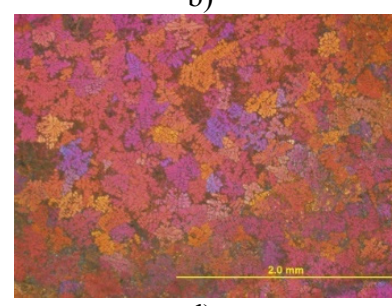

d)

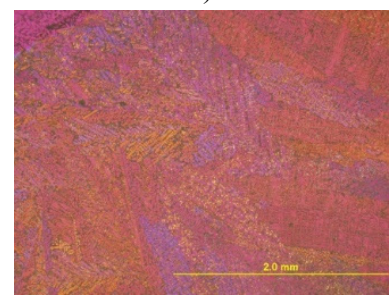

f)
Fig. 3. Optical images of the surface of alloys: A356 (a), A356_VT (b), A356+0.2wt $\%$ C (c), A356 $+0.2 \mathrm{wt} \% \mathrm{C} \_\mathrm{VT}(\mathrm{d})$, $\mathrm{A} 356+1 \mathrm{wt} \% \mathrm{C}(\mathrm{e}), \mathrm{A} 356+1 \mathrm{wt} \% \mathrm{C} \_\mathrm{VT}(\mathrm{f})$. 
The samples with DNPs and without the vibration treatment was not observed a decrease in average grain size $(460 \mu \mathrm{m}$ for the A356 alloy $+0.2 \mathrm{wt} \% \mathrm{C} ; 429 \mu \mathrm{m}$ for the A356 alloy $+1 \mathrm{wt} \% \mathrm{C}$, Fig. 3a, 3c, 3e) compared to the initial A356 alloy $(423 \mu \mathrm{m})$. However, the combined effect of the DNPs injection and vibration treatment on the melt during the crystallization process greatly affected the size and structure of the grains. The average grain size decreased goes down from $449 \mu \mathrm{m}$ (the A356 alloy after vibration, Fig. $3 b$ ) to $176 \mu \mathrm{m}$ (the A356 alloy $+0.2 \mathrm{wt} \% \mathrm{C}$ after vibration, Fig.3d) and to $386 \mu \mathrm{m}$ (the A356 alloy $+1 \mathrm{wt} \% \mathrm{C}$ after vibration, Fig.3f). Drop in grain size may be associated with the formation of new crystallization centres and a significant containment of the crystal growth due to their destruction under the oscillatory effect arising during the vibration treatment of the melt. The $0.2 \mathrm{wt} \%$ DNPs injection provided a greater number of crystallization centers after the vibration effect. The $1 \mathrm{wt} \%$ DNPs injection led to agglomerate into larger micron particles and this does not allow to use them effectively as modifiers. The DNPs content of $0.2 \mathrm{wt} \%$ cannot be considered limiting as there are intermediate values up to $1 \mathrm{wt} \%$ that require further research. The density of all alloys did not change and was about $2.6 \mathrm{~g} / \mathrm{cm}^{3}$.

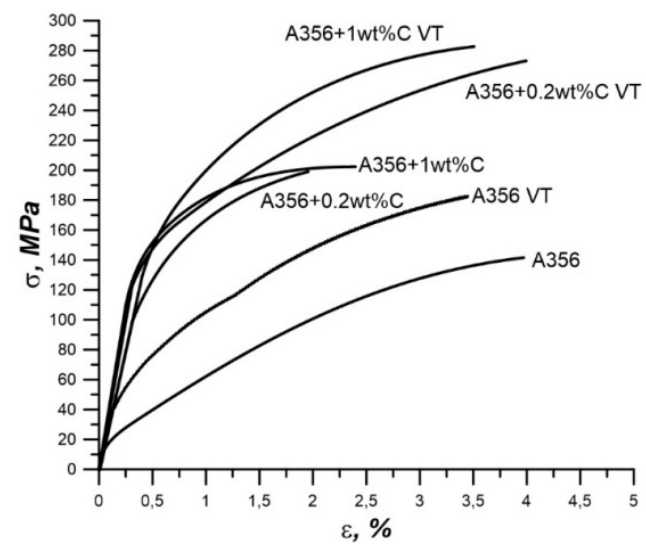

Fig. 4. Mechanical properties (engineering curves) of A356 alloy and A356-based composite alloys before and after the vibration effect.

Table 1. Properties of A356 alloy and A356-based composites containing diamond particles before and after the vibration effect.

\begin{tabular}{|l|c|c|c|c|c|}
\hline Alloy & $\begin{array}{c}\text { YS, } \boldsymbol{\sigma}_{\mathbf{0}, \mathbf{2}} \\
\mathbf{M P a}\end{array}$ & $\begin{array}{c}\mathbf{U T S}, \boldsymbol{\sigma}_{\mathbf{B}} \\
\mathbf{M P a}\end{array}$ & $\boldsymbol{\varepsilon}, \boldsymbol{\%}$ & $\mathbf{d}, \boldsymbol{\mu m}$ & $\boldsymbol{\rho}, \mathbf{g} / \mathbf{c m}^{\mathbf{3}}$ \\
\hline $\mathrm{A} 356$ & 33 & 143 & 4 & 423 & 2.56 \\
\hline $\begin{array}{l}\text { A356+0.2 } \\
\text { wt\%C }\end{array}$ & 142 & 199 & 2 & 460 & 2.54 \\
\hline $\begin{array}{l}\text { A356+1 } \\
\text { wt\%C }\end{array}$ & 150 & 204 & 2.4 & 429 & 2.57 \\
\hline A356 VT & 74 & 183 & 4 & 449 & 2.55 \\
\hline $\begin{array}{l}\text { A356+0.2 } \\
\text { wt\%C VT }\end{array}$ & 155 & 273 & 4 & 176 & 2.58 \\
\hline $\begin{array}{l}\text { A356+1 } \\
\text { wt\%C VT }\end{array}$ & 169 & 282 & 3.5 & 386 & 2.6 \\
\hline
\end{tabular}

Mechanical tensile testing (Figю 4) showed that there was an increase in the yield strength from 33 to $142 \mathrm{MPa}$ for A356 alloy $+0.2 \mathrm{wt} \% \mathrm{C}$ compared to $150 \mathrm{MPa}$ for A356 alloy $+1 \mathrm{wt} \% \mathrm{C}$; the tensile strength from 143 to 199 and $204 \mathrm{MPa}$ for(A356 alloy, respectively, with 0.2 and $1 \mathrm{wt} \%$ of $\mathrm{C}$ followed by unsignificant reduction in plasticity compared to the initial A356 alloy. The ductility of aluminum alloy with the introduction of 0.2 wt $\%$ DNPs reduced from $4 \%$ to $2 \%$. Increasing the amount of DNPs in the alloy up to $1 \mathrm{wt} \%$ did not significantly affect the ductility, that was $2.4 \%$.

It can be observed (fig.4) that the vibration treatment of the A356 melt helps to improve tensile test outcomes: the yield strength from 33 to $74 \mathrm{MPa}$ and the tensile strength from 143 to $183 \mathrm{MPa}$ while maintaining the plasticity, in comparison with the initial A356 alloy. The injection of $0.2 \mathrm{wt} \%$ DNPs with subsequent vibration treatment of the melt allows increasing the yield strength from 74 to $155 \mathrm{MPa}$ and the tensile strength from 183 to $273 \mathrm{MPa}$ while maintaining the plasticity (4\%) compared to the A356 alloy after vibration. A further increase in DNPs concentration to $1 \mathrm{wt} \%$ demonstrates high mechanical properties of the alloy: there is an increase in the yield strength from 74 to $169 \mathrm{MPa}$ and the tensile strength from 183 to $282 \mathrm{MPa}$.

Table 1 presents the mechanical and structural properties of the A356 alloy and A356-based composites containing diamond particles before and after the vibration effect.

The increase in A356 alloys with DNPs strength properties compared to the initial A356 alloy may be related to the presence of structure heterogeneities that significantly affect the ultimate mechanical properties of the materials. In work [30] the vibration treatment of an aluminum alloy containing particles was used, which allowed improving the structure and mechanical properties without reducing its ductility. The mechanical properties are formed mostly due to the contribution of three mechanisms resulting from the presence of diamond particles in the structure of composites. The first mechanism is the load transfer from the particle to the matrix. This mechanism was due to the influence of hardening particles on composite properties [11]. Under specified conditions nanoparticles can change the direction of growth of the defect by orienting it from the boundary into the grain volume. The implementation of the second mechanism (the Hall-Petch law) [11] seems to become possible due to a dramatic decrease in the grain size for composites (A356+0.2 wt $\%$ C) from 423 to $176 \mu \mathrm{m}$ after the vibration effect, in comparison with the initial alloy. The second mechanism is typical for the alloys containing $0.2 \mathrm{wt} \%$ of DNPs with a significant modifying effect. The third mechanism is the Orowan one, where non-cut nanoparticles can prevent dislocations from moving. As a result, the dislocation line bends and forms an Orowan ring around the particle.

\section{Conclusions}

We have shown the integrated positive effect of DNPs introduction and vibration treatment on A356 alloys and 
A356-based composites. It has been concluded that the composites containing $0.2 \ldots 1 \mathrm{wt} \%$ of DNPs are characterized by lower grain sizes in comparison with the initial alloy due to the formation of new crystallization centers and a significant containment of crystal growth during the vibration effect on the melt.

Low additives of DNPs jointly with vibration treatment $(0.2 \mathrm{wt} \%)$ improves mechanical properties of Al alloys. The composite mechanical properties significantly increase due to the influence of at least three mechanisms: the load transfer from the particle to the matrix, the Hall-Petch law and the Orowan mechanism.

The research was performed with the financial support within the UMNIK program (11867GU/2017) of the Russian Foundation for Assistance to Small Innovative Enterprises (FASIE).

\section{References}

1. F.C. Robles-Hernandez, J.M.H. Ramírez, R. Mackay Al-Si Alloys (Springer, Cham, 2017)

2. A.M. Samuel, G.H. Garza-Elizondo, H.W. Doty, F. H. Samuel, Mater. Des. 80, 99 (2015)

3. F. Wang, D. Eskin, J. Mi, T. Connolley, J. Lindsay, M. Mounib, Acta Mater. 116, 354 (2016)

4. Q. Gao, S. Wu, S. Lü, X. Duan, P. An, Mater. Des. 4, 79-86 (2016)

5. I. Kaldre, A. Bojarevičs, I. Grantsa, T. Beinerts, M. Kalvāns, M. Milgrāvis, G. Gerbeth, Acta. Mater. 118, 253 (2016)

6. G. Wang, Q. Wang, M. A. Easton, M. S. Dargusch, M. Qian, D. G. Eskin, D. H. StJohn, Sci. Rep. 7, 9729 (2017)

7. R.Z. Valiev, Y. Estrin, Z. Horita, T.G. Langdon, M. J. Zehetbauer, Y. Zhu, JOM. 68/4, 1216 (2016)

8. M. Zha, Y. Li, R.H. Mathiesen, R. Bjørge, H.J. Roven, Acta. Mater. 84, 42 (2015)

9. L. Sunghak, K. Dongil, S. Dongwoo, Metall. Mater. Trans. 27A, 3893 (1996)

10. C. Hongseok, J. Milton, K. Hiromi, and Li Xiaochun, Metall. Mater. Trans. A. 43, 738 (2012)

11.S. Vorozhtsov, I. Zhukov, V. Promakhov, E. Naydenkin, A. Khrustalyov, A. Vorozhtsov, JOM. 68, 12, 3101 (2016)

12. S. Vorozhtsov, L. Minkov, A. Khrustalyov, V. Dammer, I. Zhukov, V. Promakhov, A. Vorozhtsov, M. Khmeleva, JOM. 69, 12, 2653 (2017)

13. O. Kudryashova, S. Vorozhtsov, M. Stepkina, A. Khrustalev, JOM. 69, 12, 2524 (2017)
14.P.A. Vityaz, V.I. Zhornik, V.A. Kukareko, A.I. Komarov, V.T. Senyut, Modification of materials and coatings with nanosized diamond containing additives (Bel. Navuka, Minsk, 2011)

15. I.E. Kalashnikov, V.V. Kovalevsky, T.A. Chernyshova, Metals. 6, 85 (2010)

16. A. M. Staver, N. V. Gubareva, A. I. Lyamkin, E. A. Petrov, Combust. Explos. Shock Waves. 20, 100 (1984)

17. E.A. Petrov, Results and objectives of the detonation synthesis of diamonds and superhard nanomaterials, Presentation at ICPSMODM-2012 (2012)

18. V.A. Popov, M.G. Khomutov, A.S. Prosviryakov, Producing metal matrix composites with nonagglomerated nanodiamond reinforcements by consolidation of mechanically alloyed granules with liquid phase formation, in Proc. 16th Eur. Cconf. on Composite Materials (22-26 June 2014) Seville, Spain

19. A.L. Vereschagin. Properties of detonation nanodiamonds (Polzunov Altai State Technical University, Biysk technological institute, Biysk, 2005)

20. S.A. Vorozhtsov, D.G. Eskin, J. Tamayo, A.B. Vorozhtsov, V.V. Promakhov, A.A. Averin, A.P. Khrustalyov, Metall. Mater. Trans. A. 46, 7, 2870 (2015)

21. O.B. Kudryashova, D.G. Eskin, A.P Khrustalev, S.A. Vorozhtsov, Russ. J. Non. Ferr. Met. 58, 4, 427 (2017)

22. R. Haghayeghi, P. Kapranos. Mater. Lett. 105, 213 (2013)

23. F. Taghavi, H. Saghafian, Y. Kharrazi, Mater. Des. 30, 1604 (2009)

24. H. Choi, M. Jones, H. Konishi, and X. Li, Metall. Mater. Trans. A. 43, 738 (2012)

25. J. Wenming, C. Xu, W. Benjing, F. Zitian, Wu Hebao, Int. J. Adv. Manuf. Technol. 83, 167 (2016)

26. Z. Zhong, F. Zitian, D. Xuanpu, T. Bo, Pan Di and Li Jiqiang, China Foundry. 7, 1, 24 (2010)

27. Ch. Limmaneevichitr, S. Pongananpanya, Ju. Kajornchaiyakul, Mater. Des., 30, 3925 (2009)

28. A. S. Zharkov, E.A. Petrov, E.S. Ananjeva, BPMS. 10, 3, 430 (2013)

29. G.V. Sakovich, A.S. Zharkov, E.A. Petrov, nauka I tekhnologii $\mathrm{V}$ promyshlennosti [Science and Technology in Industry], 4, 53 (2011) (in Russian)

30. Q. Gao, Mater. Sci. Eng., A. 680, 437 (2017) 